\title{
Clinical Outcomes of Omalizumab as Add-on Therapy for Severe Asthma Patients
}

\author{
A.Abd EL-Sadek ${ }^{1}$, E.A.Mohamed ${ }^{1}$, H.H.Moussa ${ }^{2}$ and A.Z.El-Saeed ${ }^{1}$ \\ ${ }^{1}$ Chest Medicine Dept., Faculty of Medicine, Benha Univ., Benha, Egypt \\ ${ }^{2}$ Chest Medicine Dept., Faculty of Medicine, Kafrelsheikh Univ., Kafrelsheikh, Egypt \\ E-Mail: zakaria11@gmail.com
}

\begin{abstract}
Asthma is a genuine worldwide medical condition influencing all age gatherings, with expanding pervasiveness in many agricultural nations, rising therapy costs, and a rising weight for patients and the local area. Hypersensitive components have been involved for asthma in 50-80\% of patients and these rates are additionally relevant to patients with serious asthma. This examination planned to survey clinical results of omlizumab treatment; asthma control, decrease of asthma seriousness and compounding and specific consideration regarding medical clinic, ICU stays and oral steroid organization. Planned associate examination directed on 32 subjects with serious unfavorably susceptible uncontrolled bronchial asthma. Omalizumab was given subcutaneous, at regular intervals or month to month as indicated by changed necessities while past asthma medicine not diminished or halted. Asthma control appraisal, asthma seriousness appraisal, medical clinic stay, ICU stay, and oral steroid organization prior to beginning omalizumab and 1, 3,6 months subsequent to beginning omalizumab therapy were assessed and recorded. Following a half year of omalizumab organization their was considerable improvement of FEV1/FVC and FEV1 with critical decrease of uncontrolled cases, and huge decrease in severity.Likewise generous improvement of asthma intensifications, medical clinic affirmations, ICU confirmations and recurrence of oral steroid organization following a half year of omalizumab organizations. Omalizumab showed great outcomes for its utilization in patients with serious hypersensitive asthma, and aided in progress of lung capacities, asthma control, asthma seriousness, and decrease of asthma intensifications, ICU confirmations and use of fundamental steroid.
\end{abstract}

\section{Introduction}

Asthma is described by factor indications of wheeze, windedness, chest snugness or hack, and by factor expiratory wind current limit. The two indications and wind current constraint attributes fluctuate after some time and in force. It is a genuine worldwide medical issue influencing all age gatherings, with expanding pervasiveness in many agricultural nations, rising therapy costs, and a rising weight for patients and the community [1]. It influences an expected 300 (5-10\%) million people worldwide however represents half of the worldwide expenses of the sickness, being a clinical just as friendly problem [2].

Unfavorably susceptible components have been involved for asthma in $50-80 \%$ of patients and these rates are likewise relevant to patients with extreme asthma [3]. There is no remedy for asthma; subsequently the objective of the treatment is the accomplishment and the support of the infectious prevention and to limit future danger following a stepwise methodology. Regardless of rules for the assessment, grouping and the board of asthma, most patients, and especially those with serious asthma, experience imperfect asthma control in numerous countries [4]. The disappointment of pharmacotherapy to totally control asthma manifestations hinders personal satisfaction and functioning [5]. What's more, insufficiently controlled asthma is related with hospitalizations, crisis division visits, and efficiency loss [6].

In these terms, Omalizumab is a recombinant acculturated monoclonal counter acting agent that specifically ties to free human immunoglobulin (Ig) E, keeping it from restricting to provocative cells, consequently restraining allergen-initiated actuation and resulting asthma indications. It was affirmed by the European Medicines Agency in 2005 and its consideration in asthma the board rules has given suggestion to its utilization in patients with extreme hypersensitive asthma with headstrong reaction to high portions of breathed in steroids and long acting $\beta 2$-agonists (LABAs) and those experiencing fundamental steroid dependence [7].

The adequacy and wellbeing profile of omalizumab for the treatment of serious unfavorably susceptible asthma has been shown in a few randomized preliminaries and affirmed in genuine world studies [8] , there are not many information about long haul omalizumab treatment, especially about the consequences for hospitalizations, corticosteroid use and personal satisfaction. This examination meant to evaluate clinical results of omlizumab treatment; asthma control, decrease of asthma seriousness and worsening and specific consideration regarding emergency clinic, ICU stays and oral steroid administration.

\section{Subjects and methods}

A planned partner study led on 32 extreme unfavorably susceptible uncontrolled asthmatic patients included for treatment with omalizumab during their development in the outpatient facility of Chest Department of Benha and Kafrelsheikh University and followed up for 6 months after omlizumab organization.

\section{Incorporation rules}

1.Aged 18 years or more seasoned.

2.Serum IgE levels of 30-700 IU/mL [9].

3.Patients determined to have serious diligent hypersensitive asthma at any rate a year preceding the treatment with Omalizumab as were as per ( NAEPP 2007) [10] :

- Low lung work (FEV1, score of under $60 \%$ of anticipated).

- Frequency of manifestations as the day progressed, night stirs each night, salvage medicine a few times in day; extreme restriction of active work, more than 
1exacerbation requiring foundational steroid in a year ago, need of high portion ICS and LABA for treatment.

4.Subjects who acknowledged to take part in the investigation.

\section{Prohibition standards}

1.Pregnant and bosom taking care of patients.

2.Current smoker patients.

3.Patients with at least one Omalizumab claims during the a year prior to the beginning time frame were barred to guarantee that the example included new initiators of omalizumab treatment.

4.Subjects who wouldn't partake in the examination.

5.Patients with COPD, cardiovascular proplems, renal imparement.

\section{Procedure \\ All patients will be exposed to the accompanying. \\ - History taking and clinical assessment.}

- Asthma control evaluation as per (GINA, 2019)1 at 1,

3, 6 months Table (1).

- Asthma seriousness evaluation as per (NAEPP, 2007)10 at 1, 3, 6 months Table (2)

- CBC.

- Liver work tests (AST, ALT, bilirubin).

- Kidney work tests (urea, creatinine).

- Pulmonary work test, utilizing gadget (Spirotik, Geratherm Medical AG, Germany)

- Serum Na, K, Ca.

- Serum basal IgE level before start treatment.

- All information will be gathered and statically broke down.

Table (1) Asthma control assessment (GINA, 2019).

\begin{tabular}{llll}
\hline Did the patient has any of the following in last 4weeks & Yes (1) & No (0) & Total \\
\hline Day time asthma symptoms more than twice/week? & & & \\
Any night waking due to asthma? & & \\
SABA reliever for symptoms more than twice/week? & & \\
Any activity limitation due to asthma? & & \\
\hline
\end{tabular}

Well controlled (0), partially controlled (1-2), Uncontrolled (3-4)

Table (2) Asthma severity assessment (NAEPP, 2007).

\begin{tabular}{|c|c|c|c|c|}
\hline \multirow[t]{3}{*}{ Components of severity } & \multicolumn{4}{|c|}{ Level of severity } \\
\hline & \multirow[t]{2}{*}{ Intermittent } & \multicolumn{3}{|c|}{ Persistent } \\
\hline & & Mild & Moderate & Sever \\
\hline Symptoms & $<2$ days/week & $>2$ days/week but not daily & Daily & Throughout the day \\
\hline Night time awakenings & $<2 /$ month & 34/month & $\begin{array}{c}>1 / \text { week but not } \\
\text { nightly }\end{array}$ & Often $7 /$ week \\
\hline $\begin{array}{l}\text { Short acting beta2agonist use } \\
\text { for symptom control }\end{array}$ & $<2$ days/week & $\begin{array}{l}>2 \text { days/week but not } \\
\text { daily, and not more than } \\
1 \mathrm{x} \text { on any day }\end{array}$ & Daily & $\begin{array}{l}\text { Several times per } \\
\text { day }\end{array}$ \\
\hline
\end{tabular}

\begin{abstract}
Interference with normal activity Lung function
\end{abstract}

None
Normal FEV1 between exacerbations FEV1 $>80 \%$ predicted FEV1/FVC normal

Recommended Step for initiating treatment

Step 1
Minor limitation

FEV1 $>80 \%$ predicted FEV1/FVC normal

Step2

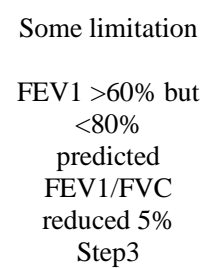

Extremely limited

FEV1 <60\% predicted FEV1/FVC reduced $>5 \%$

Step4

\section{Method}

The portion and recurrence of the medication in asthma patients were resolved by body weight and serum IgE level that should be performed before beginning omalizumab [11]. It was given in at least one infusions subcutaneous at regular intervals or month to month while past asthma medication not diminished or halted.

Moral approval:the study was led at Chest medication division of Benha and Kafrelsheikh University Hospitals after endorsement of the examination Ethical council at workforce of medication, Benha University (RECFOMBU).
Measurable investigation: The gathered information were coded, handled and broke down utilizing the SPSS (Statistical Package for Social Sciences) variant 22 for Windows ${ }^{\circledR}$ (IBM SPSS Inc. (Chicago, IL, USA).

Likelihood esteem (P-esteem) was deciphered as follow:

- Non-huge if the $\mathrm{p}$ esteem is $>0.05$

- Significant if the $\mathrm{p}$ esteem is $\leq 0.05$.

- Highly huge if the $\mathrm{p}$ esteem $<0.001$.

The accompanying tests were finished: 
1.One-path examination of the fluctuation (One-way ANOVA) was utilized to analyze between at least three free gatherings of ordinarily dispersed factors

2.Independent examples t-test was utilized to look at between two autonomous gatherings of ordinarily circulated factors

3.Chi square test $(\chi 2)$ and Fisher test used to compute contrast between subjective factors as demonstrated.

Beneficiary working trademark (ROC) examination:

Test attributes were assessed by ROC bend and included best cutoff esteem, AUC, its standard blunder (SE), and P-esteem. Also, to survey the viability of the test, gauges as affectability, explicitness, positive prescient worth (PPV), negative prescient worth (NPV), and exactness were determined at the optimal cutoff.

\section{Results}

Total number of studied asthmatic patients was 32 patients, their BMI ranged 20-33 years $(26.4+3.39)$, There were 8 patients have normal body weight, 18 patients were overweight and 6 patients were obese, duration of asthma range 22-34 years $(26.66+3.21)$ Table (3).

Within the year before starting omalizumab, usage of steroid was found in $21(65.6 \%)$ participant, Frequency of asthma exacerbations were ; two times in 6 (18.8\%) patients, four times in $6(18.8 \%)$ patients, daily exacerbations in $5(15.6 \%)$ patients and frequent in 15 $(46.9 \%)$ patients, hospital admission frequency were one time in $3(9.4 \%)$ patients , 2 times in $6(18.8 \%)$ patients , 3times in $7(21.9 \%)$ patients , 4times in $2(6.3 \%)$ patients, 5times or more in $10(31.2 \%)$ patients, ICU admission frequency was one time in $3(9.37 \%)$, two times in 3 $(9.37 \%)$ patients, three times in $4(12.5 \%)$ patients and four times in $1(3,2 \%)$ patients. Basal serum $\operatorname{IgE}$ ranged 95-650 (304.69 \pm 134.89$)$. Co morbidities in study participants were allergic rhinitis in $16(50 \%)$ patients, gastro esophageal reflux in $12(37.5 \%)$ patients Table (3).

Outcome of omalizumab administration reported significant improvement of FEV1/FVC from (59.79+ $10.53)$ to $(66.15+14.34),(\mathrm{P}=0.001)$ after one month from omalizumab treatment, like wise FEV1 substantially improved from $(50.39+9.97)$ to $(53.96+12.63)(\mathrm{P}=0.005)$, there was a significant reduction of severity, as 11 patients became moderate severity, however 21 patient still sever from original 32 sever patients ( $\mathrm{p}=.031$ and 0.005 , respectively). After 3 months of omalizumab administration, there was significant reduction in uncontrolled cases as 19 patients became partially controlled, however 13 patient still uncontrolled $(\mathrm{P}<0.001)$. There was significant reduction of severity as 5 cases became mild, 16 cases became moderate, however 11 patients still sever $(\mathrm{P}<0.001)$

After 6 months, their was substantial improvement of FEV1/FVC and FEV1 (P <0.001) of omalizumab administration with significant reduction of uncontrolled cases where 14 cases became well controlled, 18 cases became partially controlled while no cases still uncontrolled $(\mathrm{P}<0.001)$, as well as significant reduction in severity where 8 patients became intermittent, 7 patients became mild, 11 patients became moderate while 6 patients still sever $(\mathrm{P}=0.041,0.069,0.001$ and $<0.001$, respectively) Table (4).

This study reported substantial improvement of asthma exacerbations, hospital admissions,ICU admissions and frequency of oral steroid administration after 6 months of omalizumab administrations $(\mathrm{P}<0.001)$ Table (5).

Table (3) Basal characteristics data of the studied patients before initiation of omalizumab treatment.

\begin{tabular}{|c|c|c|}
\hline Items & & Cases $(n=32)$ \\
\hline \multirow[t]{2}{*}{ BMI $\left(\mathrm{kg} / \mathrm{m}^{2}\right)$} & Mean \pm SD & $26.25 \pm 3.39$ \\
\hline & Range (min-max) & $25.9(2033)$ \\
\hline \multicolumn{3}{|l|}{ Obesity } \\
\hline Normal weight & 8 & $25 \%$ \\
\hline Over weight & 18 & $56.25 \%$ \\
\hline Obese & 6 & $18.75 \%$ \\
\hline \multirow[t]{2}{*}{ Duration of the disease (years) } & Mean \pm SD & $26.66 \pm 3.21$ \\
\hline & Range (min-max) & $26.5(2234)$ \\
\hline \multicolumn{3}{|c|}{ Use of oral steroid within the year before starting treatment } \\
\hline No & & $11(34.4 \%)$ \\
\hline Yes & & $21(65.6 \%)$ \\
\hline \multicolumn{3}{|c|}{ No of asthma exacerbations within the year before starting treatment } \\
\hline two times & & $6(18.8 \%)$ \\
\hline four times & & $6(18.8 \%)$ \\
\hline Daily & & $5(15.6 \%)$ \\
\hline Frequent & & $15(46.9 \%)$ \\
\hline \multicolumn{3}{|c|}{ No of Hospital admissions for asthma within the year before starting treatment } \\
\hline 1 time & & $3(9.4 \%)$ \\
\hline 2 times & & $6(18.8 \%)$ \\
\hline 3 times & & $7(21.9 \%)$ \\
\hline 4 times & & $2(6.3 \%)$ \\
\hline 5 times & & $10(31.2 \%)$ \\
\hline No & & $4(12.5 \%)$ \\
\hline \multicolumn{3}{|c|}{ No of ICU admissions for asthma within the year before starting treatment } \\
\hline 1 time & & $3(9.4 \%)$ \\
\hline 2 times & & $3(9.4 \%)$ \\
\hline 3 times & & $4(12.5 \%)$ \\
\hline 4 times & & $1(3.1 \%)$ \\
\hline No & & $21(65.6 \%)$ \\
\hline
\end{tabular}




\begin{tabular}{llc}
\hline Basal serum IgE & $\begin{array}{l}\text { Mean } \pm \text { SD } \\
\text { Range (min-max) }\end{array}$ & $\begin{array}{c}304.69 \pm 134.89 \\
(95-650)\end{array}$ \\
\hline Table (3) Continue & & \\
\hline & Comorbidities & $16(50 \%)$ \\
allergic rhinitis & & $12(37.5 \%)$ \\
GERD & & $12(37.5 \%)$ \\
No & & \\
\hline
\end{tabular}

Continuous data expressed as mean \pm SD and range (range) Categorical data expressed as Number (\%).

Table (4) Comparison of the asthma assessment at basal, 1 month, 3 months and 6 months after starting treatment.

\begin{tabular}{|c|c|c|c|c|c|c|}
\hline & Before treatment & $\begin{array}{l}1 \text { month after } \\
\text { treatment }\end{array}$ & $\begin{array}{l}\text { 3months after } \\
\text { treatment }\end{array}$ & $\begin{array}{l}\text { 6months after } \\
\text { treatment }\end{array}$ & $\begin{array}{l}\text { Test of } \\
\text { significance }\end{array}$ & $P$ value \\
\hline FEV1/FVC & $59.79 \pm 10.53$ & $66.15 \pm 14.34$ & $68.78 \pm 19.36$ & $80.09 \pm 16.99$ & $\mathrm{~F}=38.301$ & $<0.001^{*}$ \\
\hline $\operatorname{FEV1}(\%)$ & $50.38 \pm 9.97$ & $53.96 \pm 12.63$ & $60.97 \pm 12.37$ & $68.28 \pm 15.75$ & $F=42.604$ & $<0.001^{*}$ \\
\hline FVC $(\%)$ & $83.5 \pm 8.65$ & $81.13 \pm 7.64$ & $83.09 \pm 5.71$ & $83.53 \pm 5.19$ & $\mathrm{~F}=3.092$ & 0.108 \\
\hline \multicolumn{7}{|c|}{ ACT (Asthma control test) } \\
\hline Well controlled & $0(0 \%)$ & $0(0 \%)$ & $0(0 \%)$ & $14(43.8 \%)$ & $\mathrm{MH}=12.406$ & $<0.001^{*}$ \\
\hline Partially controlled & $0(0 \%)$ & $4(12.5 \%)$ & $19(59.4 \%)$ & $18(56.2 \%)$ & & $<0.001^{*}$ \\
\hline Uncontrolled & $32(100 \%)$ & $28(87.5 \%)$ & $13(40.6 \%)$ & $0(0 \%)$ & & $<0.001 *$ \\
\hline \multicolumn{7}{|c|}{ Asthma severity } \\
\hline Intermittent & $0(0 \%)$ & $0(0 \%)$ & $0(0 \%)$ & $8(25 \%)$ & $\mathrm{MH}=17.324$ & $0.041^{*}$ \\
\hline Mild & $0(0 \%)$ & $0(0 \%)$ & $5(15.6 \%)$ & $7(21.8 \%)$ & & 0.066 \\
\hline Moderate & $0(0 \%)$ & $11(34.3 \%)$ & $16(50 \%)$ & $11(34.4 \%)$ & & $<0.001 *$ \\
\hline Severe & $32(100 \%)$ & $21(65.6 \%)$ & $11(34.4 \%)$ & $6(18.8 \%)$ & & $<0.001 *$ \\
\hline
\end{tabular}

Continuous data expressed as mean $\pm \mathrm{SD}$,Categorical data expressed as Number (\%) within columns ,F:
Repeated measures ANOVA ,MH: marginal homogeneity test, * Statistically significant if $\mathrm{P}<0.05$.

Table (5) comparison of asthma characteristics at basal and $6 \mathrm{~m}$ after starting omalizumab.

\begin{tabular}{|c|c|c|c|c|}
\hline Items & Basal & At 6 months & Test of significance & P value \\
\hline \multicolumn{5}{|c|}{ No of asthma exacerbations } \\
\hline Yes & $32(100 \%)$ & $12(37.5 \%)$ & $\mathrm{MCN}=64.140$ & $<0.001 *$ \\
\hline No & $0(0 \%)$ & $20(62.5 \%)$ & & $<0.001 *$ \\
\hline \multicolumn{5}{|c|}{ No of Hospital admissions } \\
\hline Yes & $12(84.4 \%)$ & $6(40.6 \%)$ & $\mathrm{MCN}=32.145$ & $<0.001 *$ \\
\hline No & $5(15.6 \%)$ & $19(59.4 \%)$ & & $<0.001 *$ \\
\hline \multicolumn{5}{|c|}{ No of ICU admissions } \\
\hline Yes & $11(34.4 \%)$ & $0(0 \%)$ & $\mathrm{MCN}=34.056$ & $<0.001 *$ \\
\hline No & $21(65.6 \%)$ & $32(100 \%)$ & & $<0.001 *$ \\
\hline \multicolumn{5}{|c|}{ Use of oral steroid } \\
\hline Yes & $21(65.6 \%)$ & $0(0 \%)$ & $\mathrm{MCN}=72.160$ & $<0.001 *$ \\
\hline No & $11(34.4 \%)$ & $32(100 \%)$ & & $<0.001 *$ \\
\hline
\end{tabular}

Categorical data expressed as Number $(\%)$ within columns, MCN: McNeman's test, * Statistically significant if $\mathrm{P}<0.05$.

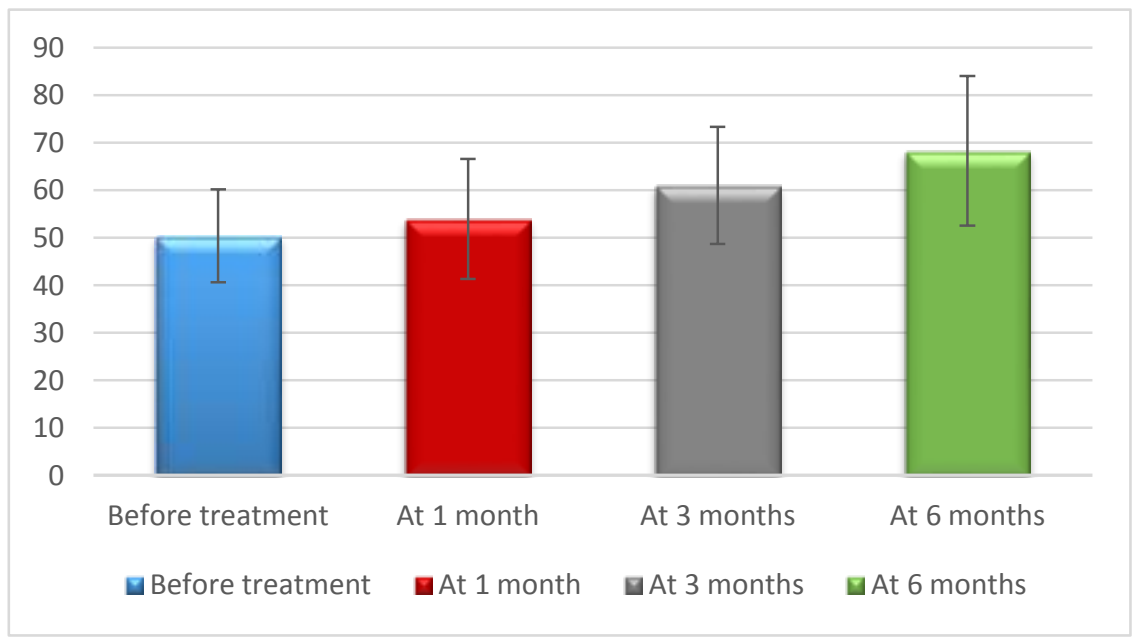

Fig (1) FEV1 (\%) at basal, 1 month, 3 months and 6 months after starting treatment. 


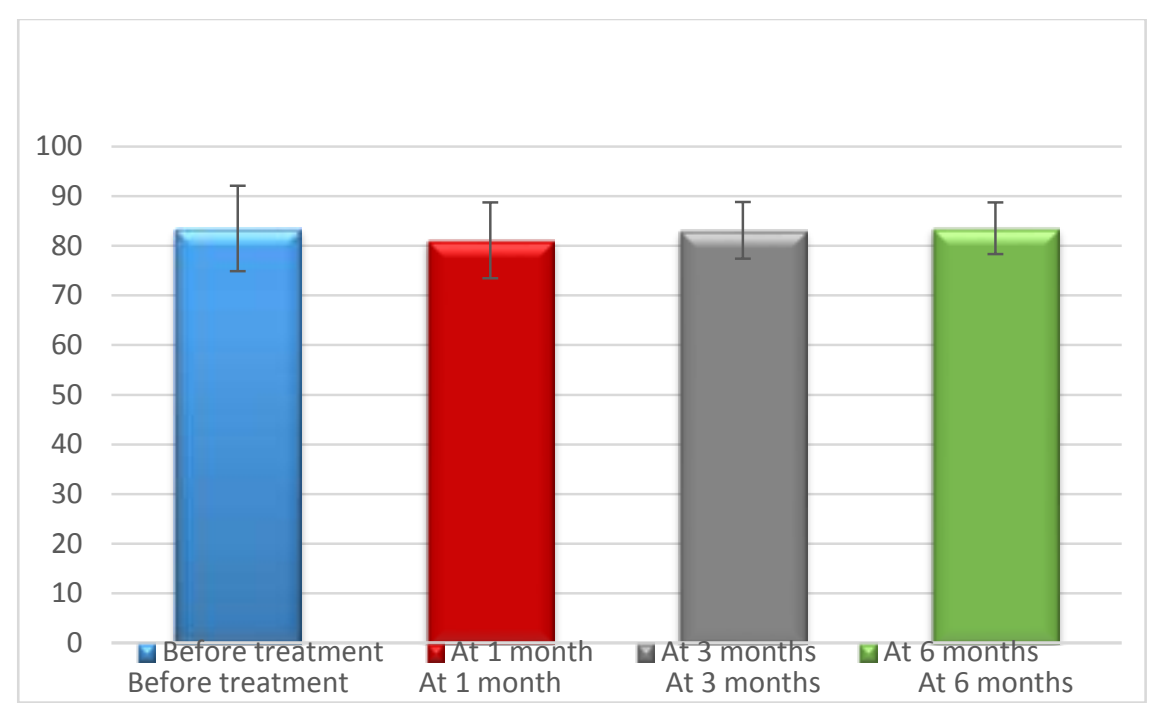

Fig (2) FVC (\%) at basal, 1 month, 3 months and 6 months after starting treatment.

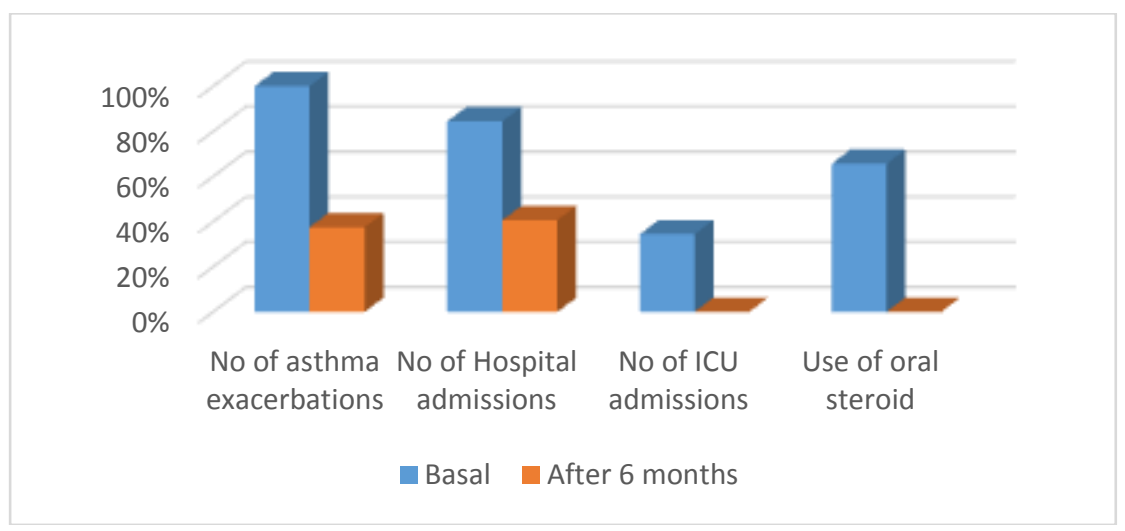

Fig (3) Asthma characteristics at basal and $6 \mathrm{~m}$ after starting omalizumab.

\section{Discussion}

Omalizumab endorsed by the European Medicines Agency in 2005 and its consideration in asthma the board rules has given suggestion to its utilization in patients with serious hypersensitive asthma [7]. The viability and security profile of omalizumab for the treatment of serious unfavorably susceptible asthma has been exhibited in a few randomized preliminaries and affirmed in genuine world studies [8].

This current examination exhibits following up of 32 cut off asthmatic patients who got omalizumab for a half year, The investigation showed critical improvement of FEV1/FVC from $(59.79+10.53)$ to $(66.15+14.34)$, $(\mathrm{P}=0.001)$ following one month from omalizumab treatment, similar to savvy FEV1 generously improved from $(50.39+9.97)$ to $(53.96+12.63)(\mathrm{P}=0.005)$, there was a huge decrease of seriousness, as 11 patients became moderate seriousness, anyway 21 patient actually cut off from unique 32 cut off patients, ( $\mathrm{p}=.031$ and 0.005, individually) and following 3 months of omalizumab organization the examination showed huge improvement of FEV1/FVC $(\mathrm{P}=0.012)$ and increment FEV1 from
$(50.39+9.97)$ to $(60.97 \pm 12.37)(\mathrm{P}<0.001)$ this is in concurrence with Schumann et al., [12] examination that revealed asignificant improvement of supreme estimations of FEV1 just as the \% anticipated in patients after a 16-week treatment period as FEV1 expanded from $2.05 \mathrm{~L} \pm 0.77 \mathrm{~L}$ to $2.31 \mathrm{~L} \pm 0.84 \mathrm{~L}(\mathrm{P}<0.05)$.

Additionally following 3 months our investigation showed asignificant decrease in uncontrolled cases as 19 of 32 uncontrolled patients turned out to be mostly controlled $(\mathrm{P}<0.001)$ and this is in concurrence with Korn et al., [13] who contemplated 280 patients with extreme unfavorably susceptible asthma over omalizumab treatment for a half year and revealed checked decrease of day by day asthma side effects and nighttime enlightenments by $69.1 \%$ and $72.3 \%$ individually ( $\mathrm{p}<0.001$ ), following 4 months,

This examination detailed generous improvement of FEV1/FVC and FEV1 (P <0.001) following a half year of omalizumab organization, likewise connected with huge decrease of uncontrolled situations where; 14 cases turned out to be very much controlled , 18 cases turned out to be halfway controlled no still uncontrolled cases $(\mathrm{P}<0.001)$, this is in agreemen with Canonica et al., 14 investigation, 
anyway the later utilized (ACQ) not (GINA control asssesement) to asses asthma control as it incorporated a cross-sectional stage $(\mathrm{n}=357)$ and a longitudinal stage $(\mathrm{n}$ $=123$ ): during the longitudinal stage, patients got omalizumab month to month and were followed-up for a year; $95 \%$ accomplished asthma control (ACQ < 4) at both 6 and a year of omalizumab treatment; ACQ score improved following 6 and a year $(\mathrm{P}<0.0001)$, most patients accomplished infectious prevention at a half year, which was kept up until a year (responders. Additionally following a half year our examination showed critical decrease in asthma seriousness, where 8 patients became discontinuous, 7 patients got gentle , 11 patients became moderate while 6 patients still extreme (yet controlled) $(\mathrm{P}=0.84,0.069,0.001$ and $<0.002$, individually.

This investigation showed huge improvement of FEV1/FVC and FEV1 with successive month to month organization of omalizumab with most extreme advantage at a half year just as, significant progressive improvement of asthma control at 1, 3 and a half year where; 14 patient turned out to be very much controlled, 18 patients turned out to be incompletely controlled, and no patients still uncontrolled by a half year of omalizumab, in like manner steady decrease of seriousness at 1, 3 and a half year of organization of the medication where; 8 patients became irregular, 7 patients got gentle, 11 patients became moderate while 6 patients still extreme.

This investigation revealed generous improvement of asthma intensifications following a half year of therapy where; $20(62.5 \%)$ patients had no intensifications $(\mathrm{P}<$ 0.001) coming in concurrence with Schumann et al., 12 study that announced critical decrease of worsening rate after therapy with omalizumab where from $3.99 \pm 6.49$ at benchmark to $1.0 \pm 1.87$ following four months of the therapy, $(\mathrm{P}<0.0001)$, additionally in concurrence with Vignola et al., 15 examination that included twofold visually impaired, equal gathering, placebo-controlled on 405 patients inside 28 weeks of omalizumab therapy that showed that [20.6\% (43/209)] of omalizumab treated patients experienced at any rate one compounding contrasted and fake treatment $[30.1 \%(59 / 196)](\mathrm{P}=0.02)$ and the mean pace of intensifications during the therapy time frame was lower with omalizumab than with fake treatment $(0.25$ and 0.40 separately; $\mathrm{P}=0.02)$.

In this investigation there is a critical decrease by $46.4 \%$ in number of cases that required medical clinic affirmation from $28(87.5 \%$ ) patients in the prior year therapy to $14(40.6 \%)$ patients following a half year of omalizumab therapy $(\mathrm{p}<0.001)$, this is in concurrence with Barnes et al., 16, who announced decrease of hospitalizations rate by $61 \%$ in the a year postomalizumab inception, comparably, Adel et al., 17 and Korn et al.,. 13

Additionally, in this examination there is a critical decrease in ICU affirmation rate from 11 (34.4\%) patients in the prior year to $0(0 \%)$ patient a half year subsequent to beginning omalizumab treatment related with huge decrease in recurrence of oral steroid organization from 21 patients $(65.6 \%) 1$ year before to 0 patient $(0 \%)$ a half year after omalizumab organization $(\mathrm{P}<0.001)$ and this is in concurrence with Barnes et al., 16 investigation that showed that, the mean absolute amount of oral corticosteroid recommended each year was diminished by $34 \%$ between the a year pre-and post-omalizumab initiation,and during the a year post-omalizumab commencement, 87 patients $(64 \%)$ halted/diminished OCS use by $20 \%$ or more and $66(49 \%)$ halted OCS completely.

\section{Conclusion}

Omalizumab exhibited great outcomes for its utilization in patients with extreme hypersensitive asthma and aided in progress of lung capacities, asthma control , reduction of asthma seriousness, pace of asthma intensifications, ICU confirmations because of asthma and use of foundational steroid .The most extreme advantages of omalizumab were acquired after in any event a half year after organization.

\section{Reference}

[1] Global Initiative for Asthma. Global strategy for asthma management and prevention, 2019. Update 2019 and Online Appendix, Vol.11, PP.855, 2019.

[2] G.Senna, M.Guerriero, P.L.Paggiaro. SANI-Severe Asthma Network in Italy: a way forward to monitor severe asthma. ClinMolAllergy, Vol.15, PP.9, 2017.

[3] D.E. Shaw, A.R.Sousa, S.J.Fowler. Clinical and inflammatory characteristics of the European UBIOPRED adult severe asthma cohort. EurRespir J, Vol. 46, PP. 1308-1321, 2015.

[4] I.Abraham, A.Alhossan, C.S.Lee. "Real-life" effectiveness studies of omalizumab in adult patients with severe allergic asthma: systematic review. Allergy, Vol.71, PP.593-610, 2016.

[5] K.Niebauer, S.Dewilde, J.Fox-Rushby. Impact of omalizumab on quality-of-life outcomes in patients with moderate-to-severe allergic asthma. Ann Allergy Asthma Immunol, Vol. 96, PP. 316-326, 2006.

[6] A.L. Fuhlbrigge, R.J.Adams, T.W.Guilbert. The burden of asthma in the United States: level and distribution are dependent on interpretation of the national asthma education and prevention program guidelines. Am J RespirCrit Care Med, Vol. 166, PP. 1044-1049, 2002.

[7] M.Humbert, R.Beasley, J.Ayres. Benefits of omalizumab as add-on therapy in patients with severe persistent asthma who are inadequately controlled despite best available therapy (GINA 2002 step 4 treatment): INNOVATE. Allergy, Vol. 60, PP. 309-316, 2005.

[8] G.J.Rodrigo, H.Neffen, J.A.Castro-Rodriguez. Efficacy and safety of subcutaneous omalizumab vs placebo as add-on therapy to corticosteroids for children and adults with asthma: a systematic review. Chest, Vol. 139, PP. 28-35, 2011.

[9] J.Ratko Djukanović, Susan. Wilson, Monica Kraft, N.Nizar. Jarjour, et al. American Journal of Respiratory and Critical Care Medicine, Vol. 170,PP. 583-593, 2011.

[10] National institute for heath and care excellence guidance/ ng80/resources/inhaled-corticosteroiddoses-pdf-4731528781, Vol. 11, PP. 569, 2018. 
[11] G.Hochhaus, L.Brookman, H.fox, C.Johnson, J.Matthews, S.Ren,et al. pharmacodynamics of omalizumab:implication for optimized dosing strategies and clinical efficacy in the treatment of allergic asthma.Curr Med Res Opin, Vol.19, PP.491-498, 2003.

[12] C.Schumann, C.Kropf, T.Wibmer, S.Rüdiger, K.M.Stoiber, A.Thielen, W.Rottbauer, C.Kroegel. Omalizumab in patients with severe asthma: the XCLUSIVE study. The Clinical Respiratory Journal, Vol. 6, PP. 215-227, 2012.

[13] S.Korn, A.Thielen, S.Seyfried, C.Taube, O.Kornmann, R.Buhl. Omalizumab in patients with severe persistent allergic asthma in a real-life setting in Germany. Respir Med. Nov, Vol.103(11), PP.1725-31, 2009.

[14] G.W.Canonica,Paola Rottoli,Caterina Bucca,Maria Cristina Zappa, Giovanni Michetti,Bruno Macciocchi, et al. Improvement of patient-reported outcomes in severe allergic asthma by omalizumab treatment: the real life observational PROXIMA study, world allergy organization journal, PP.0413018-0214-3, 2018.

[15] A.M.Vignola, M.Humbert, J.Bousquet, L.P.Boulet, S.Hedgecock, M.Blogg, H.Fox, K.Surrey. Efficacy and tolerability of anti-immunoglobulin E therapy with omalizumab in patients with concomitant allergic asthma and persistent allergic rhinitis: SOLAR. Allergy, Vol. 59, PP. 709-717, 2004.

[16] N.Barnes., Andrew Menzies-Gow, H.Adel, Mansur, David Spencer, Fran Percival, Amr Radwan, Rob Niven. Effectiveness of Omalizumab in Severe Allergic Asthma: A Retrospective UK Real-World Study, Journal of Asthma, Vol. 50:5,PP. 529-536, 2013.

[17] H.Adel. Mansur, Sapna Srivastava,Verity Mitchell, Julie Sullivan, Ismail Kasujee, Respiratory Medicine, Elsevier, March. Vol.124, PP.36-43, 2017. 